Dance training: cardiorespiratory adaptation

\title{
CHANGES IN ENERGY DEMAND OF DANCE ACTIVITY AND CARDIORESPIRATORY FITNESS DURING ONE YEAR OF VOCATIONAL CONTEMPORARY DANCE TRAINING
}

Sarah Beck1,3*, Matthew A Wyon2,3, Emma Redding1,3

1Dance Science, Trinity Laban Conservatoire of Music and Dance, London, UK ${ }_{2}$ Research Centre for Sport, Exercise and Performance, Institute for Sport, University of Wolverhampton, Walsall, UK ${ }_{3}$ National Institute of Dance Medicine and Science, London, UK

* Correspondence: Sarah Beck, Dance Science, Trinity Laban Conservatoire of Music and Dance, Faculty of Dance, Creekside, London, SE83DZ, UK. Tel: +44 (0)20 83059483. sc.beck@trinitylaban.ac.uk 
Dance training: cardiorespiratory adaptation

\section{INTRODUCTION}

Previous research, primarily in ballet and contemporary dance, has highlighted a disparity between the demand of dance training and that of high level dance performance $(12,20,26)$. For example, one study reported mean $\mathrm{VO}_{2}$ values of $17.42 \mathrm{ml} \cdot \mathrm{kg}^{-1} \cdot \mathrm{min}^{-1}$ during dance class compared to $23.34 \mathrm{ml} . \mathrm{kg}$

${ }^{1} \cdot \mathrm{min}^{-1}$ for dress rehearsal/ performance in female contemporary dancers (26). Research al so suggests that the lower recorded intensity of dance class, as well as its discontinuous nature, is not sufficient to elicit an aerobic training response $(19,24,28)$. In line with this, previous reviews have reported the cardiorespiratory fitness of contemporary, ballet, and dance sport dancers as relatively low $(2,15,22)$. This has raised questions of the suitability of training, through class and rehearsal, as adequate preparation for the physical demands of a sustained and successful career in dance. As well as general health benefits, increased cardiorespiratory fitness levels have been linked to fatigue resistance and therefore a decreased risk of injury due to distraction of focus, or inability to maintain correct technique (1). It is therefore of interest to document the extent of physiological adaptation to vocational contemporary dance training, in terms of global cardiorespiratory fitness and movement economy, with regard to the physiological intensity experienced while performing dance specific movement.

The majority of studies in this area have undertaken cross-sectional physiological profiles of dancers across various genres, with only four studies conducting repeated measures over extended periods of time without intervention in training $(5,13,14,27)$. Very little change in aerobic capacity $\left(\mathrm{VO}_{2 \text { max }} / \mathrm{VO}_{2 \text { peak }}\right)$ or heart rate $(\mathrm{HR})$ response to the dance aerobic fitness test (DAFT) (29) is documented in these studies, with the exception of subjects participating in extended periods of performance (27). Conversely, previous research involving intervention through additional supplementary fitness training programs, both aerobic and strength based, has noted significant improvements in the same variables $(3,11,16,18)$. Results of these experimental studies concur with suggestions that dance training cannot elicit positive adaptations in markers of cardiorespiratory 
Dance training: cardiorespiratory adaptation

fitness. However, there are many limitations to these studies as outlined in a previous review (4). As dance activity, in multiple genres, is unanimously described as intermittent and of moderate- to highintensity it is also questioned if the variables frequently reported are sensitive to the specific physiological development of dancers. For example, dancers rarely work maximally or aerobically for long periods of time, therefore the lack of increase in $\mathrm{VO}_{2 \max }$ measures, as found by previous literature, may be expected. Variables such as movement economy and lactate threshold have been less frequently examined in dance populations; however, these factors seem highly relevant given the intermittent and high skill based nature of dance activity. In particular, given the low cardiorespiratory fitness levels often documented for dancers of varying levels across various dance genres, and the highly specific nature of dance training practices, it seems likely that dancers are highly economical in their movement, allowing them to complete required sequences at a lower relative intensity and with seeming ease.

It is of interest to examine the ability of dancers to meet the energy demands of specific sequences of dance movements required in their genre in more depth, particularly in a vocational setting, where dancers develop their technical skill and work towards high-level performance. The purpose of this study is therefore to track changes in key physiological variables over one training year (academic year) in different levels of vocational contemporary dance students. It is hypothesised that significant differences will be found in the degree of change between groups for all stated variables, with significant changes only documented following the performance period in the postgraduate student group.

\section{METHODS}

\section{Experimental approach to the problem}

The study adopted a longitudinal design, where the same subjects were measured at three time-points throughout one training/ academic year: October (TP1), February (TP2), and June (TP3). Subjects were 
Dance training: cardiorespiratory adaptation

in training during academic term time throughout this year. Identical testing procedures were used at each time-point to allow direct comparison of measures. Dependent variables were : aerobic capacity $\left(\mathrm{VO}_{2 \text { peak }}\left[\mathrm{ml} \mathrm{kg}^{-1} \cdot \mathrm{min}^{-1}\right]\right)$ and lactate threshold $\left(\mathrm{LT}\left[\mathrm{ml} \cdot \mathrm{kg}^{-1} \cdot \mathrm{min}^{-1}\right.\right.$ and $\left.\left.\% \mathrm{VO}_{2 \text { peak }}\right]\right)$, as determined by a treadmill test to volitional exhaustion; and relative oxygen uptake $\left(\mathrm{VO}_{2}\left[\mathrm{ml}^{\mathrm{kg}} \mathrm{kg}^{-1} \cdot \mathrm{min}^{-1}\right]\right)$, heart rate $(\mathrm{HR}$ $\left[\right.$ b. $\left.\left.\mathrm{min}^{-1}\right]\right)$, percentage of maximal aerobic capacity $\left(\% \mathrm{VO}_{2 \text { peak }}\right)$, and percentage of lactate threshold (\%LT) during performance of a standardised dance se quence. These variables allowed representation of cardiorespiratory fitness and relative demand/ intensity of dance movement, as well as any changes in these across time.

\section{Subjects}

Required sample size was calculated, based upon data provided by Wyon \& Redding (27), as 25 (12 per group) based upon magnitude of effect at $90 \%$ confidence intervals (8). However, only sixteen female subjects participated in this study; nine first-year undergraduate students enrolled in a Bachelor of Arts (BA) contemporary dance programme (UG), and seven postgraduate students enrolled in a Masters of Arts (MA) dance performance programme (PG). Three subjects (two UG, one PG) dropped out of the study after the first time point giving a total dropout rate of $19 \%$. Differences in the two programmes are noted, with the PG students forming a pre-professional company and touring performance work from February to June. During this touring period, the PG group selfreported typically undertaking a $1.5 \mathrm{hr}$ technique class and 1 - 2.5 hours of rehearsals each day, and performed an average of once per week for $1.25 \mathrm{hrs}$. Before the touring period PG students typically undertook 1.5 hrs of technique class, followed by $4-5$ hrs of rehearsals each day. UG students throughout the year typically have $3 \mathrm{hrs}$ of technique class per day, plus choreography and academic classes. Data from research documenting the physiological demands of these activities is available in a previous review (4). 
Dance training: cardiorespiratory adaptation

The study was approved by the Trinity Laban Research Ethics Committee. All subjects were over 18 years of age (range 18-23 years). All subjects were informed of possible risks and benefits of their participation prior to signing an approved informed consent document.

\section{Procedures}

Immediately prior to testing at each time-point, all subjects completed a Medical Physical Activity Readiness Questionnaire (Par-Q) and individual height and weight were measured. Each subject completed two separate test procedures at each time-point as outlined below.

\section{1) Cardiorespiratory Fitness Testing}

Each subject completed a treadmill test to volitional exhaustion to determine their individual LT and aerobic capacity $\left(\mathrm{VO}_{2 \max } / \mathrm{VO}_{\text {2peak }}\right)$. The British Association of Sport and Exercise Science (BASES) approved test protocol for determining LT (21), was modified based upon pilot te sting with the study population, to consist of a minimum of five and a maximum of nine, three-minute stages with an increase of $1 \mathrm{Km} \cdot \mathrm{h}^{-1}$ at each stage at a consistent incline of $0.5 \%$. This modification is in line with recommendations of Wyon (25) to reduce the total time of the test to "minimise trauma to the subject". A warm up was completed prior to each test consisting of two minutes walking at $6.0 \mathrm{Km} . \mathrm{h}^{-}$ ${ }^{1}$ and four minutes jogging at the subjects' start speed (range: $7.0-9.0 \mathrm{Km} \cdot \mathrm{h}^{-1}$ ). Throughout the test, oxygen uptake values were collected via subjects wearing a telemetric gas analyser (Metamax 3B, Cortex Biophysik $\mathrm{GmbH}$, Germany) and heart rate data were continuously monitored using a heart rate monitor (Polar, Polar Electro, Finland). The test protocol was discontinuous to allow capillary blood samples to be collected from the earlobe within 30 seconds of the end of each test stage, before the speed was increased. Samples were then analysed for blood lactate levels (Lactate Pro, Arkray Inc, Japan). All tests continued until volitional cessation, with data additionally monitored for meeting at least two of the following criteria: HR within $10 \mathrm{~b} \cdot \mathrm{min}^{-1}$ of age-predicted maximum, respiratory exchange ratio ( $\mathrm{RER}$ ) above $1.15, \mathrm{VO}_{2}$ plateau despite increase in speed, or inability to match treadmill speed. Whether or not individuals attained true $\mathrm{VO}_{2 \max }$ was determined based upon meeting at least 
Dance training: cardiorespiratory adaptation

two these criteria, with additional definition of $\mathrm{V} \mathrm{O}_{2}$ plateau as a final stage increase in workload recording an increase in relative $\mathrm{VO}_{2}$ of less than $2 \mathrm{ml} \cdot \mathrm{kg}^{-1} \cdot \mathrm{min}^{-1}(9,17)$. If criteria were not satisfied then the highest 30 -second average value was taken as attained $\mathrm{VO}_{2 \text { peak. }}$. Criteria for attainment of $\mathrm{VO}_{2 \max }$ were not consistently satisfied within the data set, therefore all values were reportedas $\mathrm{VO}_{2 \text { ped. }}$. Lactate Threshold (LT) was estimated via a plot of measured blood lactate concentrations against treadmill speed for each individual subject. The threshold point was determined as the corresponding $\mathrm{VO}_{2}\left(\mathrm{ml} \cdot \mathrm{kg}^{-1} \cdot \mathrm{min}^{-1}\right)$ value above which net increases in lactate production were observed to result in sustained increase in blood lactate concentration (23).

\section{2) Dance Sequence Testing}

Each subject performed a four minute, pre-choreographed movement sequence, which was based on stage three of the DAFT (29), within a dance studio. This stage was designed to be representative of dance class intensity (29) and has a low technical skill level to minimise the effect of learning and technical ability on measurements, and instead all ow an assessment of physiological response sto the task across time. A pilot test was conducted to ensure the complexity and intensity of the sequence was appropriate. Subjects learned the sequence within the first testing session at time point 1. Subjects were required to wear the same telemetric gas analyser and heart rate monitor as used during the treadmill test throughout the movement. Measurements enabled determination of any changes in the relative intensity for each minute of the movement sequence across time -points. Each minute was expressed as $\mathrm{VO}_{2}\left(\mathrm{ml}^{\mathrm{kg}} \mathrm{kg}^{-1} \cdot \mathrm{min}^{-1}\right), \mathrm{HR}\left(\mathrm{b} \cdot \mathrm{min}^{-1}\right), \% \mathrm{VO}_{2 \text { peak }}$, and \%LT for each individual. Subjects were also filmed while performing the sequence to allow visual checks of consistency in movement across subjects and time-points. Any apparent anomalies in physiological data were crossreferenced with video footage to en sure this was not due to incorrect execution of movement. 
Dance training: cardiorespiratory adaptation

\section{Data Analysis}

All breath-by-breath gas data were smoothed, allowing for more accurate data analysis by removing considerable variability in individual data points (10). Following suggestions of BASES (10) and methods adopted in previous dance specific literature (6) a six breath average was applied, followed by a reduction to 30 second average values. All data points were reported as relative $\mathrm{VO}_{2}\left(\mathrm{ml}^{\mathrm{k}} \mathrm{kg}^{-1} \cdot \mathrm{min}^{-}\right.$ $\left.{ }^{1}\right)$, relative to individual body mass due to the weight bearing nature of the activity. Individual body mass was measured at each time-point immediately prior to the treadmill test to enable accurate calculation of $\mathrm{VO}_{2}$ as $\mathrm{ml} \cdot \mathrm{kg}^{-1} \cdot \mathrm{min}^{-1}$, therefore any changes in individual body mass throughout the course of the study were taken into account in results. Weight of metabolic equipment was not considered in relative calculations due to its negligible weight $(1 \mathrm{~kg})$. For analysis of demand during the dance sequence the mean $\mathrm{VO}_{2}$ value $\left(\mathrm{ml} \mathrm{kg}^{-1} \cdot \mathrm{min}^{-1}\right)$ for the final minute (minute 4) was used to calculate mean $\% \mathrm{VO}_{2 \text { peak }}$ and mean $\% \mathrm{LT}$.

\section{Statistical Analysis}

The accepted $p$-value for significance was set at $p<0.05$ for all statistical analyses. All variables were checked for normal distribution using the Shapiro-Wilk statistic. A 2(group) x 3(time) repeated measures ANOVA with within-subjects difference contrast was run on each variable to assess for difference between groups across time. Effect size is reported via partial eta squared values $\left(p \eta_{2}\right)$. Care was taken in interpretation of results due to limitations of small sample size. Variables were: $\mathrm{VO}_{2 \text { peak }}$

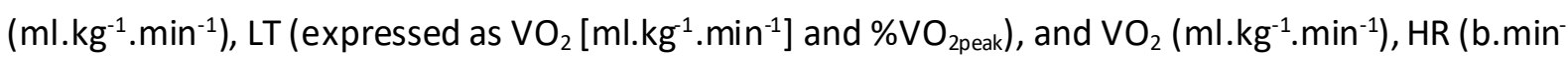
$\left.{ }^{1}\right), \% \mathrm{VO}_{2 \text { peak, }}$ and $\% \mathrm{LT}$ for the final minute of the dance sequence. Data are presented as mean \pm standard deviation (SD).

\section{RESULTS}

Basic anthropometric data collected at time-point 1, including: age (yrs), stature (m), mass (Kg), and calculation of body mass index $\left(\mathrm{BMl}, \mathrm{Kg} / \mathrm{m}^{2}\right)$ are displayed in Table 1 for each fully participating subject 
Dance training: cardiorespiratory adaptation

$(N=13)$. Although height and weight were measured at each time point, data from time-points 2 and 3 are not shown.

Table 1 here

Key findings demonstrate significant changes in the relative intensity of the dance sequence across time. A peak in cardiorespiratory fitness was found in the PG dancers at TP2, however overall fitness level decreased over time in both groups. All variables were normally distributed.

\section{Cardiorespiratory Fitness Testing}

Statistical analyses revealed no significant main effect of time or group on $\mathrm{VO}_{2 \text { peak }}$ values, but did detect a significant time*group interaction $\left(\mathrm{p}<0.05, \mathrm{p \eta}_{2}=.999\right)$. No further significant differences were detected, despite an increase in mean $\mathrm{VO}_{2 \text { peak }}$ evident at TP2 in the PG group (Table 2). Mean $\mathrm{VO}_{2 \text { peak }}$ values recorded throughout the study ranged from $39.56 \pm 4.07$ to $48.48 \pm 4.27 \mathrm{ml} \cdot \mathrm{kg}^{-1} \cdot \mathrm{min}^{-1}$ over all three time-points.

No significant differences were found in LT (expressed as either $\mathrm{ml} \cdot \mathrm{kg}^{-1} \cdot \mathrm{min}^{-1} \mathrm{or} \% \mathrm{VO}_{2 \text { peak }}$ ) across time in either group. Trends of, non-significant, change across time (Table 2) show the highest mean value for both groups occurring at TP2 for LT $\left(\mathrm{ml}^{\mathrm{kg}} \mathrm{kg}^{-1} \cdot \mathrm{min}^{-1}\right)$ and a contrasting gradual increase across time in both groups when expressed as $\% \mathrm{VO}_{2 \text { peak }}$.

Table 2 here

\section{Dance Sequence Testing}

Significant main $\left(p<0.05, \mathrm{p \eta}_{2}=.998\right)$ and within-subject effects $\left(\mathrm{p}<0.05, \mathrm{p \eta}_{2}=.963\right)$ of time were found for mean $\mathrm{VO}_{2}\left(\mathrm{ml} \mathrm{kg}^{-1} \cdot \mathrm{min}^{-1}\right)$ values during the final minute of the dance sequence with a significant 
Dance training: cardiorespiratory adaptation

difference found between TP3 and previous measures (at TP1 and TP2) for time $\left(p<0.01, p \eta_{2}=.984\right)$ and between TP1 and TP2 for time*group interaction $\left(p<0.05, p \eta_{2}=.918\right)$. Differences between groups were not analysed due to the absence of a main effect for the group factor, however as is evident in table 3 , both groups decreased their mean $\mathrm{VO}_{2}$ over time, with the lowest values observed at TP3. A notable difference in the degree of change between TP1 and TP2 is also evident between groups.

A significant within-subjects effect of time was found between mean $\mathrm{HR}\left(\mathrm{b} \cdot \mathrm{min}^{-1}\right.$ ) values during the final minute of the dance sequence $\left(p<0.05, \mathrm{p \eta}_{2}=.653\right)$. However, no significant within-subjects contrasts were found, despite decreased values across time in both groups as evident in Table 3.

Table 3 here

No significant differences were found in mean $\% \mathrm{VO}_{2 \text { peak }}$ values during the final minute of the dance sequence, despite a notable difference in the degree of change between TP1 and TP 2 betweengroups as seen in Figure 1.

Figure 1 here

A significant main time*group interaction was found for mean $\% \mathrm{LT}$ during the final minute of the dance sequence $\left(p<0.05, p \eta_{2}=.999\right)$, along with significant within-subjects effects of time $\left(p<0.01, p \eta_{2}\right.$ $=.935)$ and time*group interaction $\left(p<0.05, \mathrm{p \eta}_{2}=.827\right)$. Within-subjects contrasts revealed $a$ significant difference for time between TP1 and TP2 $\left(p<0.01, p \eta_{2}=.991\right)$ and between TP3 and previous measures (TP1 and TP2) $\left(p<0.05, \mathrm{p \eta}_{2}=.925\right)$, and for time*group interaction between TP1 and TP2 $\left(p<0.05, \mathrm{p \eta}_{2}=.970\right)$. Differences between groups were not analysed due to the absence of a main effect for the group factor, however as is evident in Figure 2, both groups decreased their mean 
Dance training: cardiorespiratory adaptation

\%LT over time, with the lowest values observed at TP3. A notable difference in the degree of change between TP1 and TP2 is also evident between groups, as in mean $\mathrm{VO}_{2}\left(\mathrm{ml} \cdot \mathrm{kg}^{-1} \cdot \mathrm{min}^{-1}\right)$ data.

Figure 2 here

\section{DISCUSSION}

The primary finding of this study was that the relative intensity of the dance movement sequence demonstrated greater changes throughout the year than measures of $\mathrm{VO}_{2 \text { peak }}$ and LT. Furthermore, results indicate a high specificity in cardiorespiratory adaptation to the training undertaken, with significant differences found between time-points and significant time*group interactions reported.

Firstly, it is of note that the $\mathrm{VO}_{2 \text { peak }}$ of subjects in the present study fell within the range reported in a previous systematic literature review of fitness in contemporary dance, which was documented as $39.2 \pm 1.9$ to $50.7 \pm 7.5 \mathrm{ml} \cdot \mathrm{kg}^{-1} \cdot \mathrm{min}^{-1}$ (2). Throughout the year, a gradual decline in $\mathrm{VO}_{2 \text { peak }}$ is noted in both groups from TP1 to TP3 with a peak in values of the PG group at TP2. Although change across time was non-significant, the significant time*group interaction reported does suggest a difference in the degree of change in $\mathrm{VO}_{2 \text { peak }}$ values across time between groups, with the $\mathrm{PG}$ group displaying larger fluctuations in reported mean values across the year. This is perhaps reflective of the previously outlined fluctuations in the training schedule of the PG students, between rehearsal time (Sept-Feb) and touring/performance time (Feb-June), compared to the relative consistency of the UG training schedule throughout the year. For both groups the lowest $\mathrm{VO}_{2 \text { peak }}$ values were reported at TP3. This is largely in agreement with previous research, which found no significant change over a period of monitoring aerobic fitness $(5,14)$. A study by Koutedakis et al. (11) in professional ballet dancers attempted to explain the decline in fitness measured at the end of the year as related to fatigue and antecedents of overtraining, suggesting an influence of the timing of data collection and aspects of a dancer's schedule at that time on values obtained. In contrast to previous research (27), the significant 
Dance training: cardiorespiratory adaptation

increase in $\mathrm{VO}_{2 \text { peak }}$ values seen in the $\mathrm{PG}$ group occurred just before the beginning of the performance period and was not maintained post-performance period. Wyon and Redding (27) previously documented no significant change in markers of aerobic fitness (HR during stage 5 of the DAFT) over a rehearsal period, but a significant change over the subsequent performance period in professional contemporary dancers. These findings agreed with the previous body of research that suggested that rehearsal intensity is not sufficient to elicit an aerobic training effect, but the higher recorded intensity of performance may be. The contrasting result of the present study, that aerobic fitness increased during the rehearsal period and decreased during the performance period, may be explained by methodological differences. Notably, the Wyon and Redding (27) study monitored changes in aerobic fitness based upon subjects' heart rate during dance specific movement (DAFT) and therefore may be more reliably compared to the relative intensitydata presented for the dance sequence in the present study. However, in the current study, although lower values were maintained post-performance period, the significant reduction in relative demand following the rehearsal period is still presented in contrast to previous literature.

Some similar trends to those observed in $\mathrm{VO}_{2 \text { peak }}$ are noted in $\mathrm{LT}\left(\mathrm{ml} . \mathrm{kg}^{-1} \cdot \mathrm{min}^{-1}\right)$ values throughout the year, with the lowest mean value for the UG group occurring at TP3 and a peak in values of the PG group at TP2. Overall, LT was more stable throughout the year in both groups than $\mathrm{VO}_{2 \text { peak, }}$ with no significant changes observed. However, when expressed as $\% \mathrm{VO}_{2 \text { peak, }}$ LT displayed a non-significant trend of gradual increase throughout the year in both groups. Typically, LT is expressed as $\% \mathrm{VO}_{2 \text { peak }}$ as it represents the capacity of the individual to work anaerobically within their overall cardiorespiratory capacity; however, in the present study this presents a challenge in analysis due to the variability around attainment of true $\mathrm{VO}_{2 \max }$. Criterion for satisfaction of $\mathrm{VO}_{2 \max }$ were only obtained in $48.7 \%$ of tests conducted throughout the study and only two subjects satisfied the criteria on all three of their individual test occasions. Therefore the $\mathrm{VO}_{2 \text { peak }}$ data presented may not be an accurate representation of subjects' true capacity. However, all subjects were able to surpass the intensity $\left(\mathrm{VO}_{2}\left[\mathrm{ml} \cdot \mathrm{kg}^{-1} \cdot \mathrm{min}^{-}\right.\right.$ 
Dance training: cardiorespiratory adaptation

${ }^{1}$ ]) at which they reached individual LT on all tests undertaken throughout the study. Dancers rarely work maximally or aerobically for long periods of time, but may intermittently work at intensities close to the LT; therefore, LT may be a more familiar and applicable measure. Guidetti et al. (7) comment on the importance of relating measurements to individual ventilatory and anaerobic thresholds in ballet dancers, as they found these proved more sensitive to detect differences between groups of varying skill levels compared to $\% \mathrm{VO}_{2 \max }$ or $\% \mathrm{HR}$ reserve or absolute HR. Therefore, the inclusion of measurements of anaerobic/ lactate thresholds should be an important consideration for future cardiorespiratory fitness testing in dance populations.

Lastly, a significant reduction in the degree of physiological effort (relative intensity) required to complete the dance sequence was observed in both groups over time. Significant decreases throughout the year were particularly evident for mean $\mathrm{VO}_{2}\left(\mathrm{ml}^{\mathrm{kg}} \mathrm{kg}^{-1} \cdot \mathrm{min}^{-1}\right)$ and $\% \mathrm{LT}$ data during the dance sequence for both groups, although the degree of change from TP1 to TP2 was less in the UG group than the PG group. As previously discussed, the differences noted between groups may be due to differences in training schedule throughout the year.

In contrast to the present study, Redding and Wyon (27) reported no significant changes over the course of rehearsal periods of the same length. Very little other research has examined the physiological intensity characteristics of dance rehearsal or the adaptation in dance specific movement economy during rehearsal periods, in contrast to a larger pool of previous studies examiningclass and performance characteristics (4). Based on the findings of the present study, it may therefore be of interest to examine this more closely in future research in order to establish the degree of training adaptation possible through extended periods of dance rehearsal. In addition to $\mathrm{VO}_{2}$ and $\% \mathrm{LT}$, as discussed above, a significant main effect of time was al so noted for $\mathrm{HR}$, however no significant differences were noted over time for mean $\% \mathrm{VO}_{2 \text { peak }}$ during the dance sequence. This is suggested to be partly due to the different pattern of change displayed in $\mathrm{VO}_{2 \text { peak }}$ data throughout the year when 
Dance training: cardiorespiratory adaptation

compared to all other measured variables, which would undoubtedly impact upon $\% \mathrm{VO}_{2 \text { peak }}$ values calculated from these data. Therefore in addition to previously raised concerns about the ability of dancers to reach a true representation of $\mathrm{VO}_{2 \max }$, this may highlight an important consideration for future research regarding the validity and reliability of this measure within dance populations.

The noted reduction in the relative intensity of the dance sequence across time may provide an interesting hypothesis regarding the development of movement economy through dance training. As dance in a highly skill-based activityit stands to reason that individuals developing their technical skill and proficiency throughout a vocational training programme would become more economical in movement; in other words, would be able to complete the same movement sequence at a lower relative intensity. This adaptation is highly specific to dance movement and therefore may not be detected by more traditional cardiorespiratory fitness tests. To the knowledge of the authors movement economy has not been specifically addressed in previous dance specific research. This may be partly due to challenges in the ability to accurately measure movement economy within dance activity, due to the requirement to record $\mathrm{VO}_{2}$ at a constant power output or velocity during steady state. This may however represent a key gap for future research to further investigate and devise appropriate measurement protocols.

The influence of the adopted methodology of the present study on the applicability of findings should also be considered. As the dance sequence was conducted at a steady-state intensity below that of the $L T$, we are unable to speculate as to the effects of training on high intensity, intermittent movement. Limitations in the study sample size are also noted, with a final sample size of 13 subjects, despite a calculated required sample power of 25 . This may partly explain the lack of significant change across time in $\mathrm{VO}_{2 \text { peak }}$ and $\mathrm{LT}$, beyond the time ${ }^{*}$ group interaction detected for $\mathrm{VO}_{2 \text { peak }}$ values, al though other important factors relating to this finding, as discussed, should not be disregarded. The small sample size is likely due to the longitudinal nature of measurement as also experienced by a similar 
Dance training: cardiorespiratory adaptation

study by Wyon and Redding (27) who, from a starting sample of 22 subjects, experienced a $23 \%$ drop out rate. A final limitation is noted with regard to the specific training exposure experienced by each group, within the three training periods, throughout the year. Although, as outlined previously, consistently is noted in the UG group and difference in the PG group between rehearsal (Sept-Feb) and touring/performance time (Feb-June), a record of training exposure, detailing hours spent in class, rehearsal, and performance for each group, was not collected. These data would have allowed for a more detailed analysis of trends seen in training adaptation and all owed for further speculation of the causes of these adaptations.

\section{PRACTICAL APPLICATIONS}

Results of the present study suggest that some positive adaptation of the cardiorespiratory systems is possible through contemporary dance training and emphasize the importance of monitoring variables that closely relate to the specific training stimulus. Through a more in-depth understanding of the demands placed upon dancers within vocational training and perhaps particularly during rehearsal periods, appropriate recommendations for optimising their physical preparation for performance may be made. Particular focus may need to be directed to rehearsal periods leading up to a performance period or tour, relative to the specific demands of the performance repertoire. It is recommended that future research continue to investigate the relevance and importance of monitoring LT and movement economy in dance specific physiological research and investigate specific training methodologies to enhance these parameters.

\section{ACKNOWLEDGEMENTS}

Thanks are given to the dancers who volunteered their time to participate in this study. This work was presented at the $24^{\text {th }}$ Annual Meeting of the International Association for Dance Medicine and Science held in Basel, Switzerland, in October 2014. 
Dance training: cardiorespiratory adaptation

\section{REFERENCES}

1. Allen, N and Wyon, M. Dance Medicine: artist or athlete? Sport Ex Med , 2008.

2. Angioi, M, Metsios, G, Koutedakis, Y, and Wyon, M. Fitness in Contemporary Dance: A Systematic Review. Int J Sports Med 30: 475-484, 2009.

3. Angioi, M, Metsios, G, Twitchett, EA, Koutedakis, Y, and Wyon, M. Effects of supplemental training on fitness and aesthetic competence parameters in contemporary dance: a randomised controlled trial. Med Probl Perform Art 27: 3-8, 2012.

4. Beck, S, Redding, E, and Wyon, MA. Methodological considerations for documenting the energy demand of dance activity: a review. Front Psycho/6: 568, 2015.

5. Dahlstrom, M, Inasio, J, Jansson, E, and Kaijser, L. Physical fitness and physical effort in dancers: a comparison of four major dance styles. Impulse Int J Dance Sci Med Educ 4: 193209, 1996.

6. Guidetti, L, Emerenziani, GP, Gallotta, MC, Da Silva, SG, and Baldari, C. Energy cost and energy sources of a ballet dance exercise in female adolescents with different technical ability. EurJ ApplPhysiol 103: 315-321, 2008.

7. Guidetti, L, Gallotta, M c., Emerenziani, G p., and Baldari, C. Exercise Intensities during a Ballet Lesson in Female Adolescents with Different Technical Ability. Int J Sports Med 28: 736-742, 2007.

8. Hopkins, WG. Estimating Sample Size for Magnitude-Based Inferences. Sportscience 10: 63-70, 2006.

9. Howley, ET, Bassett, DR, and Welch, HG. Criteria for maximal oxygen uptake: reviewand commentary. Med Sci Sports Exerc 27: 1292-1301, 1995.

10. James, DVB, Sandals, LE, Wood, DM, and Jones, AM. Pulmonary gas exchange. In: Sport and Exercise Physiology Testing Guidelines: Volume II - Exercise and Clinical Testing: The British Association of Sport and Exercise Sciences Guide. Winter, EM, Jones, AM, Davison, RCR, Bromley, PD, and Mercer, T, eds. . London: Routledge, 2006.

11. Koutedakis, Y, Hukam, H, Metsios, G, Nevill, A, Giakas, G, Jamurtas, A, et al. The effects of three months of aerobic and strength training on selected performance- and fitness-related parameters in modern dance students. J Strength Cond Res Nat/Strength Cond Assoc 21: 808812, 2007.

12. Koutedakis, Y and Jamurtas, A. The Dancer as a Performing Athlete: Physiological Considerations. Sports Med 34:651-661, 2004.

13. Koutedakis, Y, Myszkewycz, L, Soulas, D, Papapostolou, V, Sul livan, I, and Sharp, NC. The effects of rest and subsequent training on selected physiological parameters in professional female classical dancers. Int J Sports Med 20: 379-383, 1999.

14. Martyn-Stevens, BE, Brown, LE, Beam, WC, and Wiersma, LD. Effects of a Dance Season on the Physiological Profile of Collegiate Female Modern Dancers. Med Sport 16: 1-5, 2012. 
Dance training: cardiorespiratory adaptation

15. McCabe, TR, Wyon, M, Ambegaonkar, JP, and Redding, E. A bibliographic review of medicine and science research in dancesport. Med Prob/ Perform Art 28: 70-79, 2013.

16. Mistiaen, W, Roussel, NA, Vissers, D, Daenen, L, Truijen, S, and Nijs, J. Effects of aerobic endurance, muscle strength, and motor control exercise on physical fitness and musculoskeletal injury rate in preprofessional dancers: an uncontrolled trial. J Manipulative Physiol Ther 35: 381-389, 2012.

17. Poole, DC, Wilkerson, DP, and Jones, AM. Validity of criteria for establishing maximal $\mathrm{O} 2$ uptake during ramp exercise tests. EurJ App/Physio/ 102: 403-410, 2008.

18. Ramel, E, Thorsson, $\mathrm{O}$, and Wollmer, P. Fitness training and its effect on musculoskeletal pain in professional ballet dancers. / Effets d' un entrainement pour ameliorer la condition physique sur les douleurs musculaires chez les danseurs de ballet professionnels. Scand J Med Sci Sports 7: 293-298, 1997.

19. Rimmer, J h., Jay, D, and Plowman, Sa. Physiological characteristics of trained dancers and intensity level of ballet class and rehearsal. Impulse Int J Dance Sci Med Educ 2: 97-105, 1994.

20. Schantz, PG and Astrand, PO. Physiological characteristics of classical ballet. Med SciSports Exerc 16: 472-476, 1984.

21. Spurway, N and Jones, AM. Lactate testing. In: Sport and Exercise Physiology Testing Guidelines: Volume II - Exercise and Clinical Testing: The British Association of Sport and Exercise Sciences Guide. Winter, EM, Jones, AM, Davison, RCR, Bromley, PD, and Mercer, T, eds. . London: Routledge, 2006.

22. Twitchett, EA, Koutedakis, Y, and Wyon, MA. Physiological Fitness and Professional Classical Ballet Performance: A Brief Review. J Strength Cond Res 23: 2732-2740, 2009.

23. Wasserman, K, Hansen, J, Sietsema, K, Sue, DY, Stringer, WW, Sun, X-G, et al. Principles of Exercise Testing and Interpretation: Including Pathophysiology and Clinical Applications. 5th Revised edition. Lippincott Williams and Wilkins, 2011.

24. Wyon, M. Cardiorespiratory Training for Dancers. J Dance Med Sci 9: 7-12, 2005.

25. Wyon, M. Testing an aesthetic athlete: contemporary dance and classical ballet dancers. In: Sport and Exercise Physiology Testing Guidelines: Volume II - Exercise and Clinical Testing: The British Association of Sport and Exercise Sciences Guide. Winter, EM, Jones, AM, Davison, RCR, Bromley, PD, and Mercer, T, eds. . London: Routledge, 2006.

26. Wyon, MA, Abt, G, Redding, E, Head, A, and Sharp, NCC. Oxygen Uptake During Modern Dance Class, Rehearsal, and Performance. J Strength Cond Res 18: 646, 2004.

27. Wyon, MA and Redding, E. Physiological monitoring of cardiorespiratory adaptations during rehearsal and performance of contemporary dance. J Strength Cond Res Nat/Strength Cond Assoc 19: 611-614, 2005.

28. Wyon, M, Head, A, Sharp, C, and Redding, E. The Cardiorespiratory Responses to Modern Dance Classes: Differences Between University, Graduate, and Professional Classes. J Dance Med Sci 6: 41-45, 2002. 
Dance training: cardiorespiratory adaptation

29. Wyon, M, Redding, E, Abt, G, Head, A, and Sharp, NCC. Development, Reliability, and Validity of a Multistage Dance SpecificAerobic Fitness Test (DAFT). J Dance Med Sci 7: 80-84, 2003.

\section{FIGURE LEGENDS}

Table 1. Mean subject anthropometric data

Table 2. Mean $\mathrm{VO}_{2 \text { peak }}$ and Lactate Threshold (LT) values for each group at each time-point

Table 3. Mean $\mathrm{VO}_{2}$ and Heart rate $(\mathrm{HR})$ values during minute four of the dance sequence for each group at each time-point

Figure 1. Changes in mean $\% \mathrm{VO}_{2 \text { peak }}$ during minute four of the dance sequence across time points for Undergraduate (UG) and Postgraduate (PG) groups

Figure 2. Changes in mean \% Lactate Threshold (LT) during minute four of the dance sequence across time points for Undergraduate (UG) and Postgraduate (PG) groups

Table 1. Mean subject anthropometric data

\begin{tabular}{|c|c|c|c|c|c|}
\hline$(N=13)$ & Group & Age (yr) & Stature $(\mathrm{m})$ & Mass (Kg) & BMI $\left(\mathrm{Kg} / \mathrm{m}^{2}\right)$ \\
\hline & \multirow{2}{*}{ UG } & 18.86 & 1.65 & 59.57 & 21.78 \\
\hline$(N=7)$ & & \pm 0.90 & \pm 0.06 & \pm 4.16 & \pm 1.32 \\
\hline Female & \multirow{2}{*}{ PG } & 22.17 & 1.67 & 58.50 & 20.97 \\
\hline$(N=6)$ & & \pm 0.75 & \pm 0.03 & \pm 3.45 & \pm 1.69 \\
\hline
\end{tabular}

- Data is presented as mean \pm standard deviation. $\mathrm{UG}=$ Undergraduate student dancers, $\mathrm{PG}=$ Postgraduate student dancers.

Table 2. Mean $\mathrm{VO}_{2 \text { peak }}$ and Lactate Threshold (LT) values for each group at each time-point

\begin{tabular}{|c|c|c|c|c|c|c|c|c|c|}
\hline & \multicolumn{3}{|c|}{$\mathrm{VO}_{2 \text { peak }}\left(\mathrm{ml} \cdot \mathrm{Kg}^{-1} \cdot \mathrm{min}^{-1}\right)$} & \multicolumn{3}{|c|}{$\mathrm{LT}\left(\mathrm{ml} \cdot \mathrm{Kg}^{-1} \cdot \mathrm{min}^{-1}\right)$} & \multicolumn{3}{|c|}{ LT (\%VO 2peak) } \\
\hline & TP1 & TP2 & TP3 & TP1 & TP2 & TP3 & TP1 & TP2 & TP3 \\
\hline UG & 43.98 & 43.80 & 39.56 & 36.95 & 37.39 & 35.49 & 83.84 & 86.01 & 89.03 \\
\hline$(N=7)$ & \pm 4.70 & \pm 4.68 & \pm 4.07 & \pm 5.56 & \pm 2.54 & \pm 3.72 & \pm 7.87 & \pm 9.12 & \pm 4.02 \\
\hline PG & 43.05 & 48.48 & 41.35 & 37.39 & 42.98 & 39.97 & 85.74 & 88.50 & 93.74 \\
\hline$(N=6)$ & \pm 2.81 & \pm 4.27 & \pm 3.50 & \pm 3.59 & \pm 5.98 & \pm 1.77 & \pm 3.79 & \pm 6.58 & \pm 3.32 \\
\hline
\end{tabular}

- Data is presented as mean \pm standard deviation. UG = Undergraduate student dancers, $P G=$ Postgraduate student dancers, TP1 = Time point 1, TP2 = Time point 2, TP3 = Time point 3 
Dance training: cardiorespiratory adaptation

Table 3. Mean $\mathrm{VO}_{2}$ and Heart rate $(\mathrm{HR})$ values during minute four of the dance sequence for each group at each time-point

\begin{tabular}{|c|c|c|c|c|c|c|}
\hline & \multicolumn{3}{|c|}{$\mathrm{VO}_{2}\left(\mathrm{ml} \mathrm{Kg}^{-1} \cdot \mathrm{min}^{-1}\right)$} & \multicolumn{3}{|c|}{ HR (b. $\min ^{-1}$ ) } \\
\hline & TP1 & TP2 & TP3 & TP1 & TP2 & TP3 \\
\hline & 29.86 & 29.82 & 25.65 & 148.00 & 151.50 & 140.50 \\
\hline$(N=7)$ & \pm 1.53 & \pm 4.20 & \pm 5.10 & \pm 13.64 & \pm 11.40 & \pm 12.66 \\
\hline PG & 33.27 & 27.34 & 25.46 & 151.50 & 141.75 & 142.17 \\
\hline$(N=6)$ & \pm 4.59 & \pm 2.59 & \pm 3.85 & \pm 23.54 & \pm 14.38 & \pm 17.34 \\
\hline
\end{tabular}

- Data is presented as mean \pm standard deviation. $U G=$ Undergraduate student dancers, $P G=$ Postgraduate student dancers, TP1 = Time point 1, TP2 = Time point 2, TP3 = Time point 3

Figure 1. Changes in mean $\% \mathrm{VO}_{2 \text { peak }}$ during minute four of the dance sequence across time points for Undergraduate (UG) and Postgraduate (PG) groups

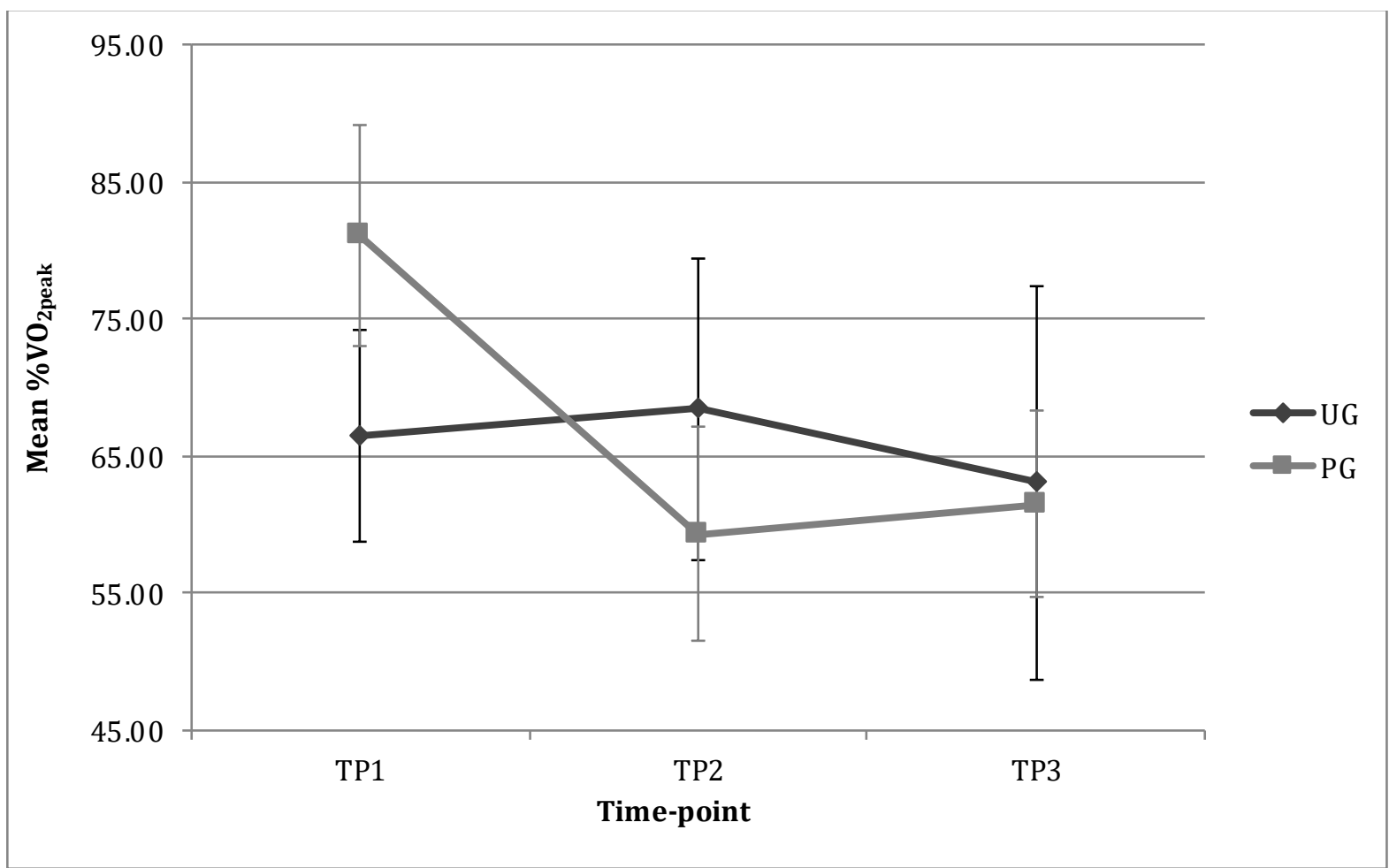

- Data is presented as mean $\pm S D$. UG = Undergraduate student dancers, $P G=$ Postgraduate student dancers, TP1 = Time point 1, TP2 = Time point 2, TP3 = Time point 3 
Dance training: cardiorespiratory adaptation

Figure 2. Changes in mean \% Lactate Threshold (LT) during minute four of the dance sequence across time points for Undergraduate (UG) and Postgraduate (PG) groups

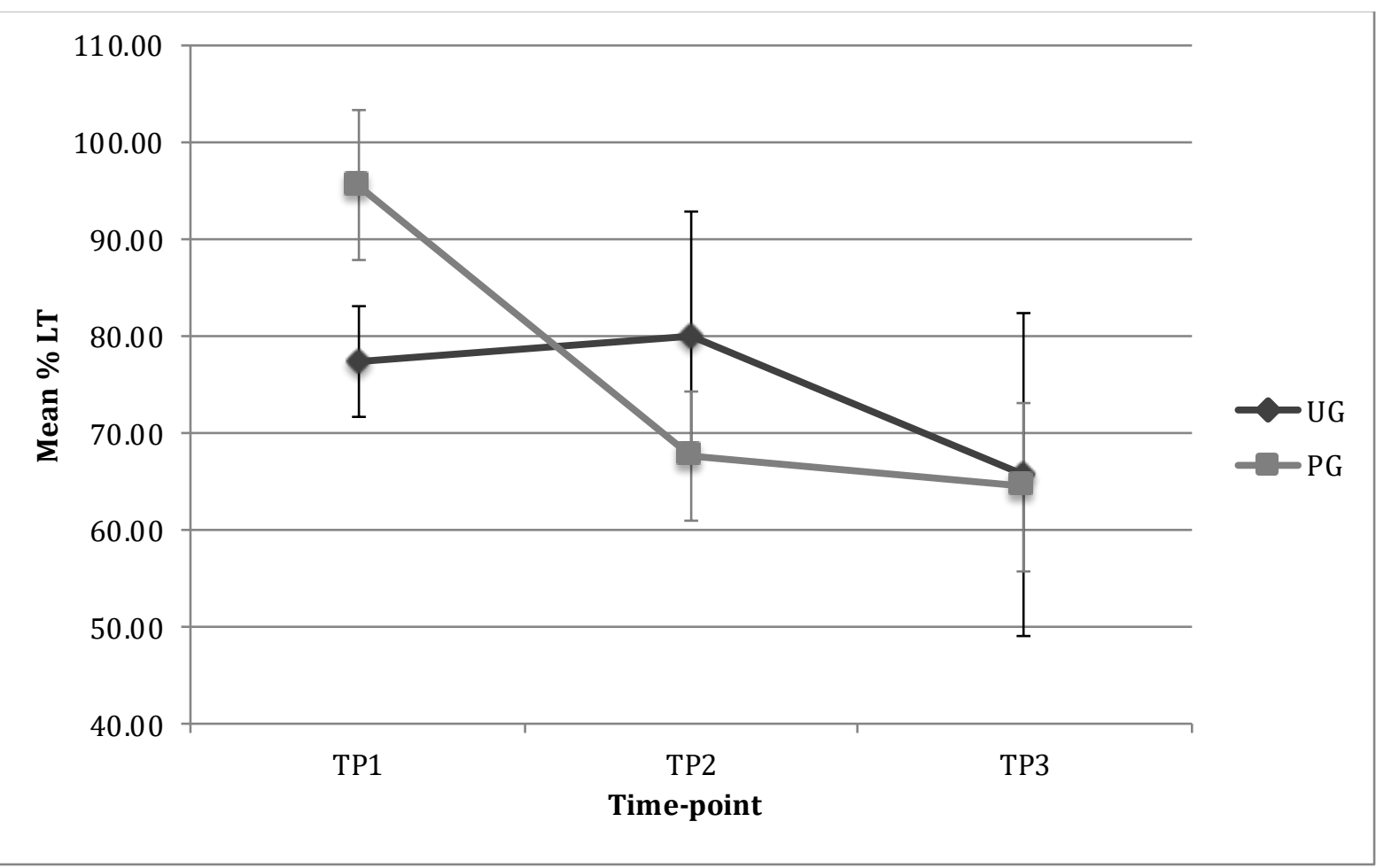

- $\quad$ Data is presented as mean $\pm \mathrm{SD}$. UG = Undergraduate student dancers, $\mathrm{PG}=$ Postgraduate student dancers, TP1 = Time point 1, TP2 = Time point 2, TP3 = Time point 3 